\title{
ENTRE O TERRITÓRIO E A PAISAGEM: RELAÇÕES ESTABELECIDAS NO SÍTIO ARQUEOLÓGICO NOVA ÍNDIA
}

Juliana Aparecida Rocha $\mathrm{Luz}^{1}$; Neide Barrocá Faccioº; João Osvaldo Rodrigues Nunes ${ }^{2}$ e Danilo Alexandre Galhardo².

Universidade Estadual Paulista "Júlio de Mesquita Filho" - UNESP, ${ }^{1}$ Curso de Geografia, ${ }^{2}$ Curso de Arqueologia, Presidente Prudente, SP. E-mail: juliluzz@yahoo.com.br, nfaccio@terra.com.br, joaosvaldo@fct.br, danilogalhardo@gmail.com.

\section{RESUMO}

Apresenta-se no presente artigo um estudo do contexto do Sítio Arqueológico Nova Índia a partir da abordagem teórico metodológica da Arqueologia da Paisagem e da Geografia Cultural. Tal contexto foi investigado com o objetivo de compreender questões relacionadas ao sistema de assentamento regional, no qual se insere o sítio em questão. Para tanto, foram realizados levantamentos bibliográficos, trabalhos de campo na área do sítio arqueológico, análises dos artefatos, de fotografias aéreas e de imagens de satélite.

Palavras-Chave: Território, Paisagem, Arqueologia

\section{BETWEEN THE TERRITORY AND THE LANDSCAPE: RELATIONS ESTABLISHED IN THE ARCHEOLOGYCAL SITE NOVA ÍNDIA}

\begin{abstract}
This paper presents a study of the context of the Nova Índia Archaeological Site based on the theoretical methodological approach of Landscape Archeology and Cultural Geography. This context was investigated in order to understand issues related to the regional settlement system, which includes the site in question. For this purpose, bibliographical surveys, fieldwork in the area of archaeological site, artifact analyzes, aerial photographs and satellite images were carried out.
\end{abstract}

Keywords: Territory, Landscape, Archaeology 


\section{INTRODUÇÃO}

Apresenta-se neste artigo o estudo do Sítio Arqueológico Nova Índia, localizado em área de média vertente, bacia do Rio Grande, Município de Barretos, SP. Na Figura 1, pode-se observar a localização do sítio na paisagem. Em sua área foram evidenciados fragmentos cerâmicos, pedras lascadas e polidas

Figura 1. Localização do Sítio Arqueológico Nova Índia na paisagem

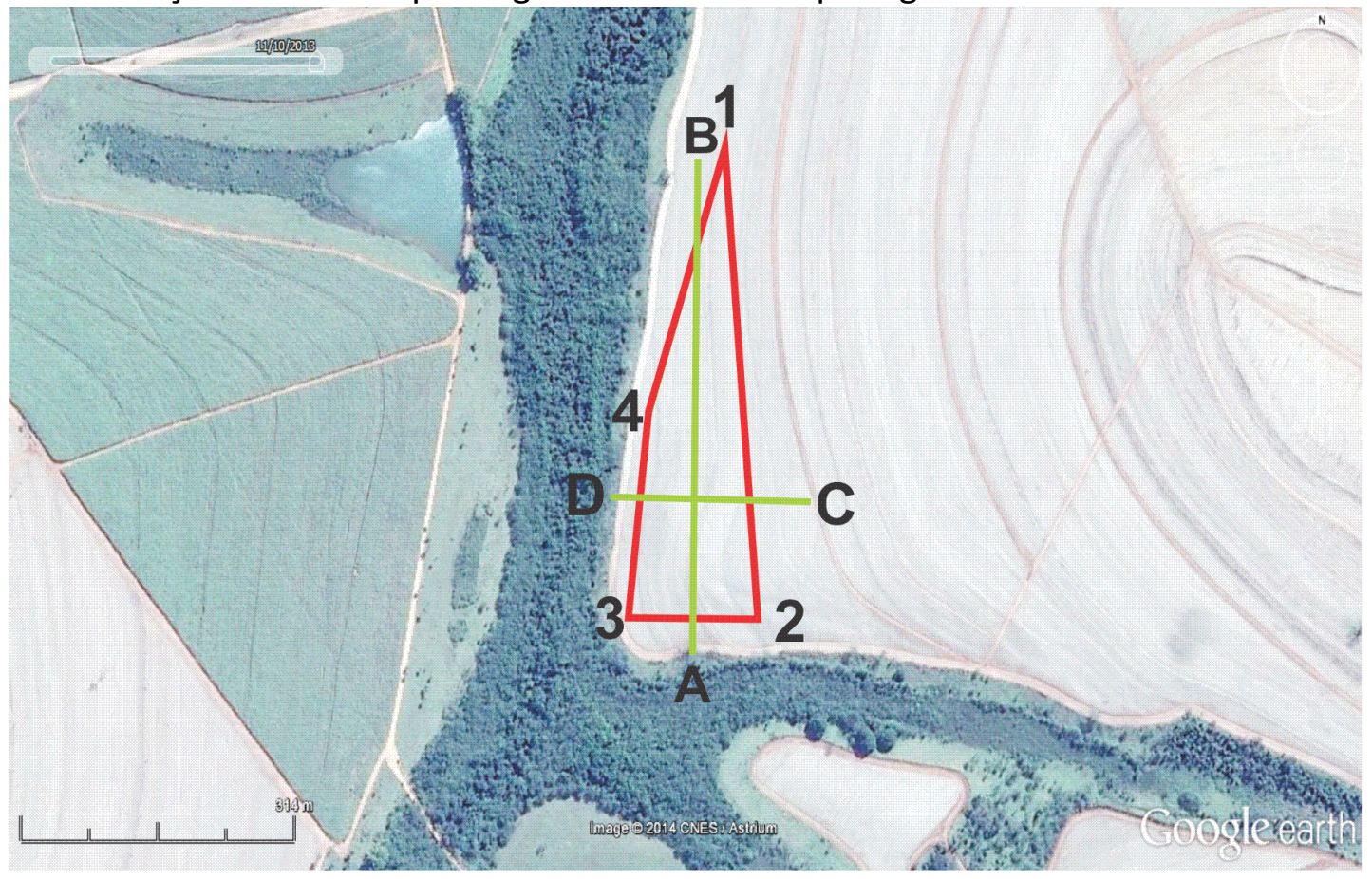

Perfis de elevação:
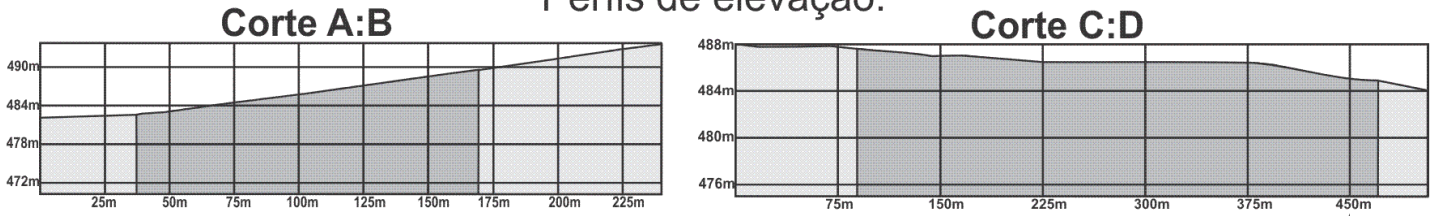

Coordenadas UTM - $22 \mathrm{k}$

1: $738836.06 \mathrm{~m} \mathrm{E} / 7720668.48 \mathrm{~m} \mathrm{~S}$

2: $738878.30 \mathrm{~m} \mathrm{E} / 7720186.79 \mathrm{~m} \mathrm{~S}$

3: $738722.61 \mathrm{~m} \mathrm{E} / 7720184.09 \mathrm{~m} \mathrm{~S}$

4: $738746.20 \mathrm{~m} \mathrm{E} / 7720391.48 \mathrm{~m} \mathrm{~S}$

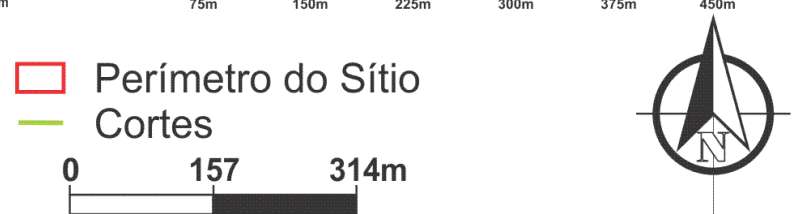

Organização: Juliana Aparecida Rocha Luz Zago (2017). Desenho: Brendo Camargo Rosa.

Fonte: Google Earth (2016)

\section{METODOLOGIA}

Realizou-se um estudo desse contexto pelo viés da Arqueologia da Paisagem e da Geografia Cultural. A Arqueologia da Paisagem, nessa pesquisa, é entendida como a união da Geografia e da Arqueologia para o entendimento final do objeto de estudo, com vistas a proceder uma pesquisa interdisciplinar. Da preocupação com o artefato, a Arqueologia caminhou para o sítio e, deste, para a paisagem e território. Este amadurecimento teórico, apresentou uma preocupação investigativa mais abrangente, de se entender não apenas uma dada sociedade humana no tempo e no espaço, restrito ao seu assentamento, e sim sua relação com a natureza. Uma das necessidades que motivaram estes desenvolvimentos foi a da Arqueologia se aproximar da Geografia, primando pelos estudos que abordam mudança e variação regional (KORMIKIARI, S/D, p. 6; CAPDEVILA, 1992; MORAIS, 2000; ANSCHUETZ, WILSHUSEN E SCHEIK, 2001; DUNCAN, 2004). 
No âmbito da análise interdisciplinar entre a Arqueologia e a Geografia, território e paisagem são conceitos chave. Segundo Zedeño (1997) paisagens são espaços perceptíveis em um relance, em contrapartida território envolve dois ou mais espaços não contíguos ou mesmo sítios ou lugares discretos. Ainda segundo a autora op. cit., paisagens são unidades cujos limites são percebidos pelo observador, enquanto território tem seus limites estabelecidos por uma sociedade que usa e controla um certo espaço. "Conceber um território como um agregado de terra, recursos naturais e objetos de fabricação humana permite integrar as dimensões espaciais, temporais e materiais em uma única história de vida empírica" (ZEDEÑO, 1997, p. 67).

A partir das reflexões teórico metodológicas sintetizadas acima, os resultados da análise do meio físico e da cultura material foram investigados com o objetivo de compreender os sistemas de assentamento dos grupos sociais que ocuparam a área ao longo do tempo e a forma como esse grupo organizou o espaço interno de suas áreas de habitação e de atividades. Para tanto, foram realizados levantamentos bibliográficos, trabalhos de campo nas áreas dos sítios arqueológicos, análises de fotografias aéreas e de imagens de satélite e análise da coleção arqueológica. Para a sistematização dos dados foram utilizadas planilhas eletrônicas e programas de Sistema de Informação Geográfica (SIG). Para a análise de curadoria das coleções líticas e cerâmicas, foram empregadas abordagens de reconstituição das cadeias operatórias de produção dos artefatos, de modo a compreender como se deu a aquisição da matéria-prima, a produção, o uso e o descarte dos instrumentos, a partir de uma análise tecno-tipológica.

O esquema de trabalho para análise da paisagem na área do sítio arqueológico levou em conta três etapas para se chegar ao resultado: 1) as formas do espaço, que constituem os dados; 2) a desconstrução do espaço, que constitui as análises: 3) o sentido do espaço, que constitui os resultados. Dessa forma, temos o esquema: dados, análises e resultados.

Também, foi realizado um levantamento e estudo de bibliografias específicas sobre o meio físico da região. Dessa forma, os dados extraídos a partir do SIG foram analisados em conjunto com as fontes bibliográficas sobre o tema.

\section{RESULTADOS e DISCUSSÕES}

A Figura 2 de localização do Sítio Nova Índia a partir dos cursos d'água nos anos de 1971 e 2015 mostra que não houve alteração na paisagem do entorno do "córrego sem denominação", no que diz respeito à realização da construção de usinas hidrelétricas na região (Usina Furnas), tal como ocorreu em outros sítios localizados em áreas distantes do Rio Grande. Assim, a área desse sítio foi pouco alterada com relação à dinâmica de transformação do curso d'água e sua planície de inundação. 
Figura 2. Localização do Sítio Arqueológico Nova Índia, a partir do curso d'água, em 1971 e em 2015

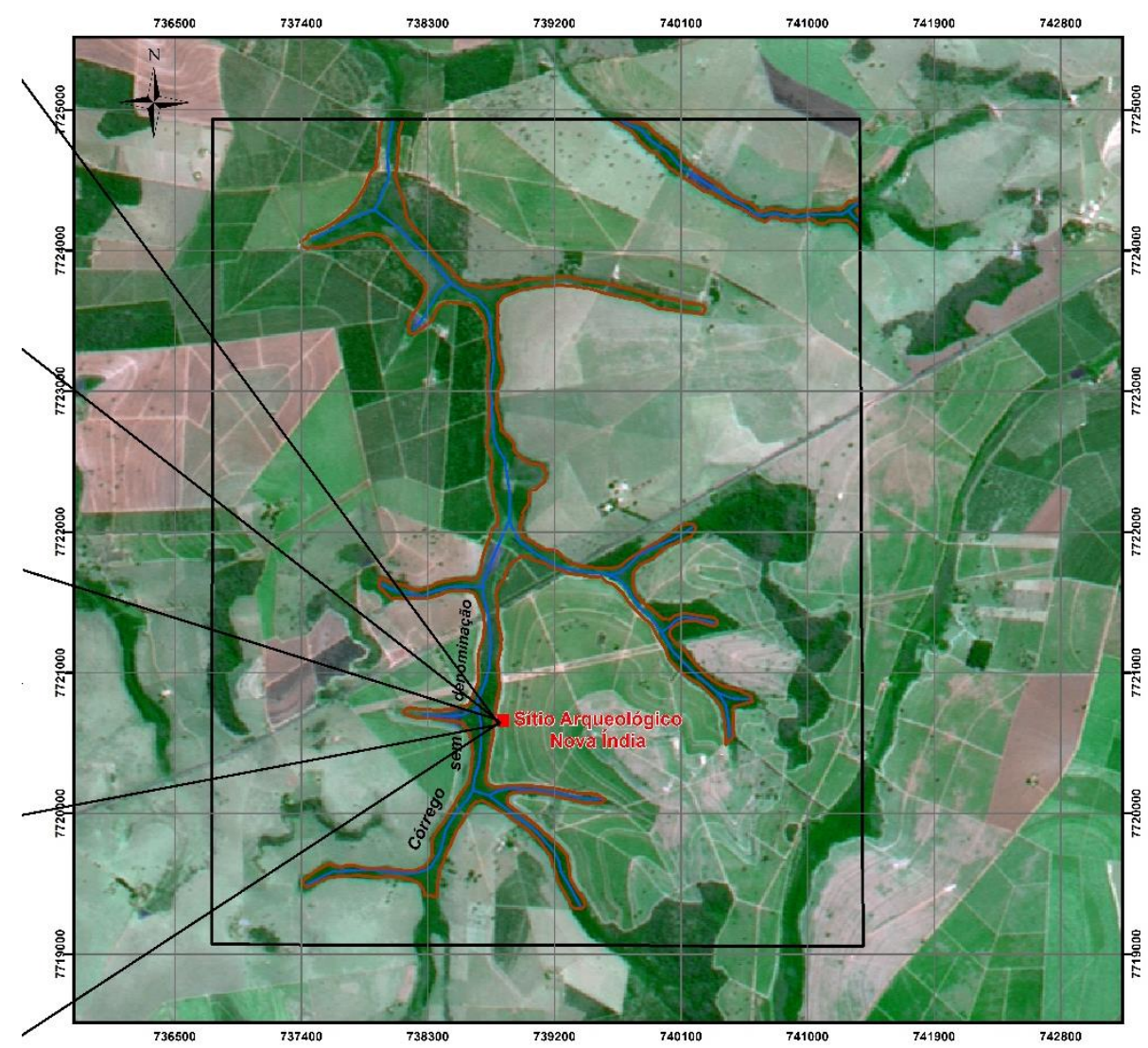

LOCALIZAÇÃO DO SíTIO ARQUEOLÓGICO NOVA INDIA EM 1971 E EM 2015
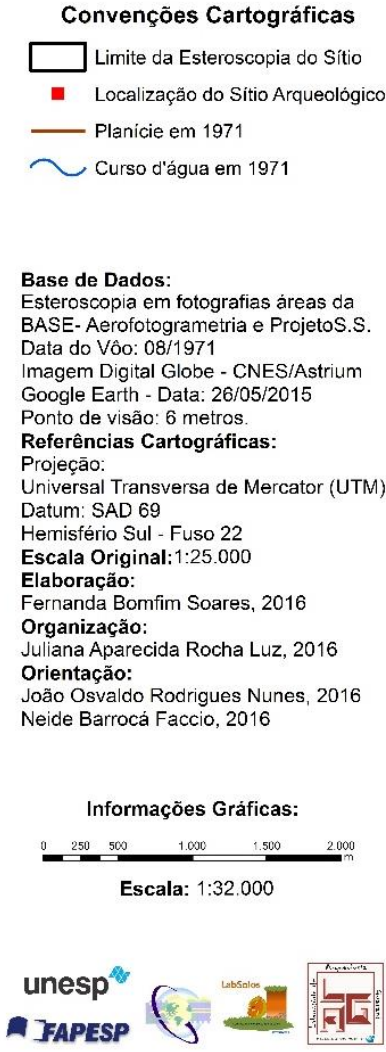

Organização: Juliana Aparecida Rocha Luz Zago. Elaboração: Fernanda Bomfim

\section{O estudo das cadeias operatórias de produção dos artefatos do Sítio Nova Índia Lítico Lascado}

Do Sítio Arqueológico Nova Índia foi analisado um total de 66 peças líticas lascadas. Na coleção analisada, foram frequentes lascas inteiras e fragmentadas, instrumentos inteiros e fragmentados, núcleos e resíduos de lascamento. Também foram frequentes as peças brutas como seixos fragmentados e blocos.

As peças foram produzidas com as matérias-primas silexito (25 peças), arenito silicificado (20 peças), quartzo (nove peças), quartzito (seis peças), arenito (presente em duas peças) e basalto (duas peças).

Na maioria dos casos, foram explorados suportes sobre seixos (45 ocorrências); na sequência, foram explorados blocos (seis ocorrências) e cristais (cinco ocorrências). Em dez casos, as peças não apresentaram córtex e, dessa forma, o suporte não pôde ser identificado.

As peças foram produzidas com as matérias-primas silexito, arenito silicificado, quartzo, quartzito, arenito e basalto. Na maioria dos casos, foram explorados seixos; na sequência, foram explorados blocos e cristais.

A hipótese de cadeia operatória de produção dos artefatos líticos lascados desse sítio, é representada por lascas retocadas. Nesse processo, uma lasca foi debitada, por meio da técnica unipolar de um seixo e posteriormente recebeu retoques que produziram gumes ativos, conforme apresenta-se na Foto 1 e na Figura 3. 
Foto 1 e Figura 3. Produto final da hipótese de cadeia operatória de produção de instrumento sobre lasca unipolar de seixo

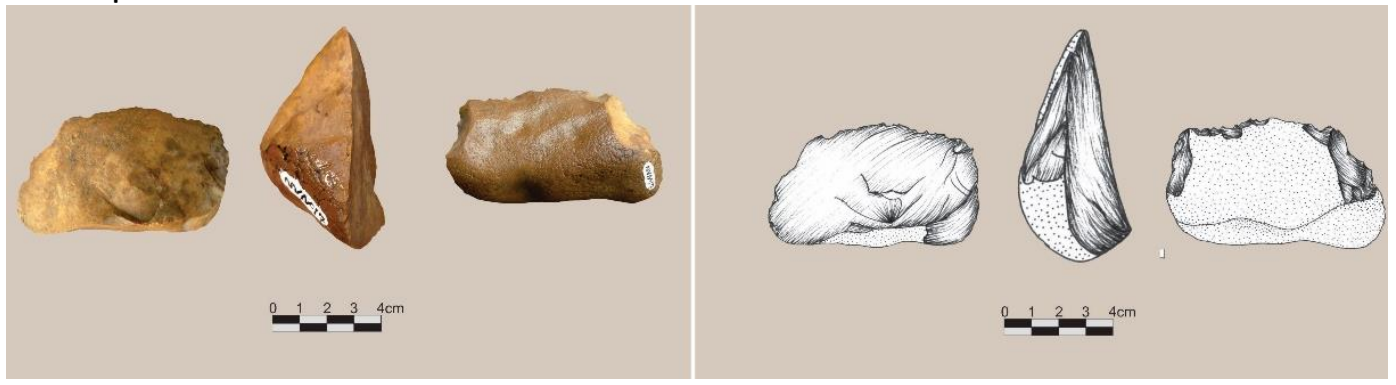

Foto: Maria Aparecida Cipriano Frizarin. Desenho: Larissa Figueiredo Daves

\section{Lítico Polido}

No Sítio Arqueológico Nova Índia foram evidenciadas cinco peças líticas polidas. As peças foram produzidas com as matérias-primas basalto (dois casos), granito (dois casos) e quartzito (um caso). Os tecno-tipos da coleção lítica polida do Sítio Nova Índia podem ser observadas nas Fotos de 2 a 5.

Fotos 2, 3, 4 E 5: Tecno-tipos da coleção lítica polida do Sítio Arqueológico Nova Índia, Município de Barretos, SP
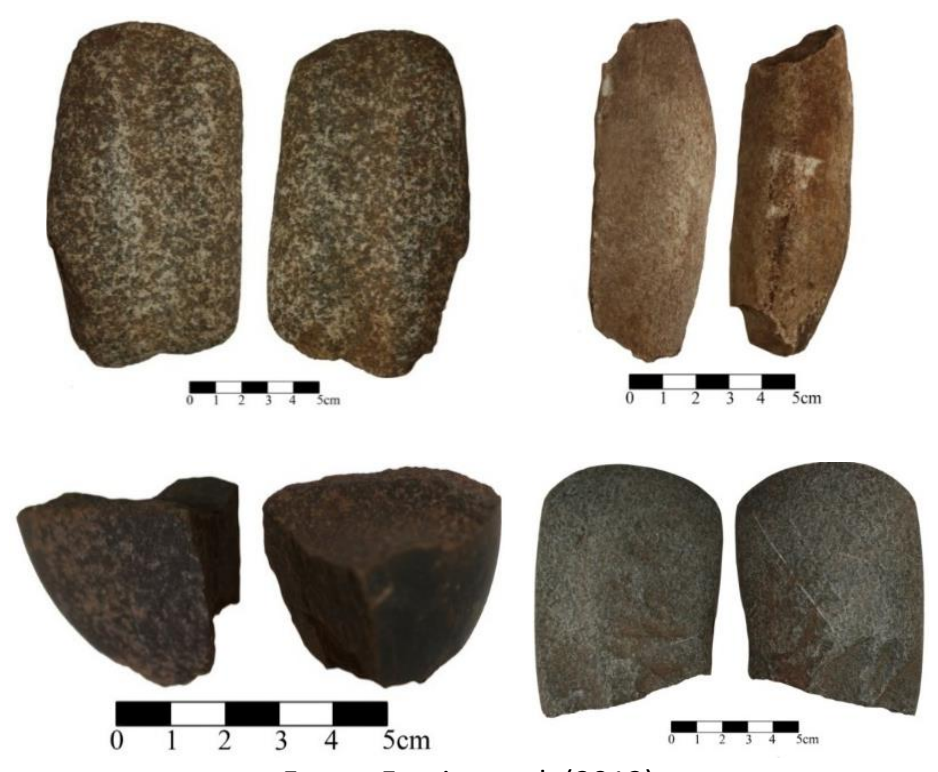

Fonte: Faccio et. al. (2012)

\section{Cerâmica}

O material cerâmico do Sítio Arqueológico Nova Índia não apresentou vasilhas cerâmicas inteiras. Dessa forma, trabalhou-se com os fragmentos individualmente, totalizando 746 fragmentos de cerâmica. Foram identificadas diversas classes, com predominância de paredes. A matéria-prima utilizada foi a argila Com uso, em alguns casos como pôde-se inferir, de antiplástico cariapé, observado em dezesseis fragmentos.

Das 61 bordas identificadas no sítio, apenas duas possibilitaram reconstituição gráfica das formas do vaso. As Figuras $\mathbf{4}$ e $\mathbf{5}$ apresentam o possível formato de duas vasilhas cerâmicas do Sítio Nova Índia. 
Figuras 4 E 5: Reconstituições de forma dos vasos a partir de borda cerâmica, respectivamente: tigela funda de boca ampliada com contorno direto inclinado externo e vaso profundo de boca constrita, com contorno extrovertido inclinado interno. Sítio Arqueológico Nova Índia, Município de Barretos SP
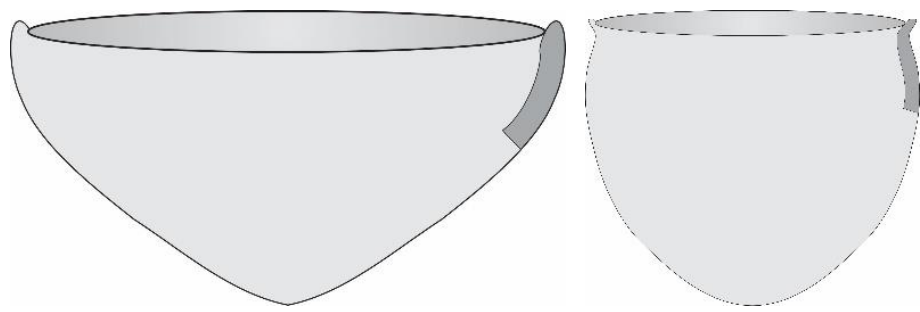

Fonte: Faccio et al. (2012)

A maioria dos fragmentos cerâmicos apresentou o acabamento superficial liso (742 peças); três fragmentos apresentaram incisão e em apenas um havia a presença de engobo branco. Houve a predominância do antiplástico mineral. Todavia, pôde-se notar a presença, em alguns fragmentos, da associação do mineral, caco moído e do cariapé.

Na relação estabelecida entre o uso de barbotina e o tipo de pasta predominou a "não utilização da barbotina" nos três tipos de pasta: plástica, intermediária e dura. Entretanto, ocorreu em alguns fragmentos a utilização da barbotina nos três tipos de pasta já citados.

\section{CONCLUSÃO}

As análises demonstram que na área em apreço podem ter sido desenvolvidas atividades domésticas, cotidianas, nas quais artefatos cerâmicos e líticos lascados e polidos puderam ser utilizados em locais de moradia, dentro do Complexo de Ocupação de um Sistema de Assentamento Agricultor Ceramista, na região norte do Estado de São Paulo. Tal sistema indica a presença de grupos indígenas Kayapó na região supracitada, haja vista a correspondência da cultura material e dos dados etno-históricos.. Os agricultores, passaram a cultivar suas roças, e por isso se tornaram seminômades. Esses ocuparam locais estratégicos, mais distantes dos grandes rios, como o Rio Grande, contudo próximos a tributários menores como os Rios Pardo e Sapucaí ou outros ribeirões e córregos, onde conseguiam matéria-prima, como argila, para a produção cerâmica ou seixos e blocos para a produção de líticos lascados e polidos. Ocuparam as vertentes onde estavam livres das enchentes e tinham visibilidade para a proteção do seu território.

Segundo a bibliografia as comunidades denominadas "kayapó" apresentavam uma mobilidade peculiar no território, caraterizada por períodos de residência numa aldeia principal coletiva e grupos seminômades que se deslocavam por períodos de um a vários meses para caça e coleta. Dessa forma, no tempo observou-se, em conjunto com as informações oferecidas pela paisagem e pelos artefatos, a ocupação de áreas interessantes para o modo de vida de distintas comunidades. No espaço observou-se a organização de atividades cotidianas, associando recursos naturais e escolhas culturais na construção da paisagem: as cadeias operatórias de produção de tais paisagens passam pela relação de escolha de locais para o assentamento, para a exploração de diferentes matérias-primas, da produção de artefatos funcionais e da utilização e descarte dos instrumentos finais.

\section{REFERÊNCIAS}

ANSCHUETZ, K. F.; WILSHUSEN, R. H.; SHEICH, C. L. Uma Arqueologia de paisagens: perspectivas e direções. Journal of Archaeological Research, vol. 9, n. 2, 2001. Traduzido por Samara Diva Ferreira Marcos.

CAPDEVILA, M.de B. Manual de Ciencia del Paisaje: teoría, métodos y aplicaciones, Org.: Editora Masson, s. a., colección de Geografía, Barcelona, 1992. 
DUNCAN, J. A paisagem como sistema de criação de signos. In: CORRÊA, R. L.; ROSENDAHL, Z. Paisagens, Textos e Identidade, Editora UFRJ, Rio de Janeiro, 2004, p. 91-132.

KORMIKIARI, M. C. N. Arqueologia da Paisagem. LABECA - MAE/USP (S/D).

MORAIS, J. L. Tópicos de Arqueologia da Paisagem. Revista do Museu de Arqueologia e Etnologia, São Paulo, 10: 3-30, 2000, https://doi.org/10.11606/issn.2448-1750.revmae.2000.109367.

ZAGO, J. A. R. L. Arqueologia da Paisagem: estudo de sítios arqueológicos no norte do estado de São Paulo (Doutorado em Geografia), faculdade de Ciências e Tecnologia, Universidade Estadual Paulista, Presidente Prudente, 2017.

ZEDEÑO, M.I. Landscapes, land use, and the history of territory formation: an example from puebloan southwest. Journal of Archaeological Method and Theory, 4(1):63-103. 1997, https://doi.org/10.1007/BF02428059. 